\title{
Histological and immunocytochemical study of cervical intraepithelial neoplasia (CIN) with associated HPV 6 and HPV 16 infections
}

\author{
D JENKINS, ${ }^{*}$ S K TAY,${ }^{*} \dagger$ D J MCCANCE, $\ddagger$ M J CAMPION,$\dagger$ P K CLARKSON, $\dagger$ \\ A SINGER $\dagger$
}

From the Departments of *Pathology and $\nmid$ Gynaecology, Whittington Hospital, and the $\ddagger$ Department of Microbiology, Guy's Medical School, London

SUMMARY Histological and immunocytochemical features of cervical intraepithelial neoplasia (CIN) associated with HPV 6 and HPV 16, either singly or in combination, were studied in 48 cases. Features of HPV infection (koilocytosis, binucleation, multinucleation, giant irregular nuclei and individual cell dyskeratosis) were present in high prevalence in both HPV 6 and HPV 16 associated CIN. Abnormal mitoses seemed to be a good indicator of .CIN and were present in about $50 \%$ of cases of CIN associated with either HPV 6 or HPV 16 infection. This finding provides no support for the view held by some investigators that associated HPV 16 infection can be predicted by the presence of abnormal mitoses. Expression of HPV antigen was shown in about $40 \%$ of cases with a slight, but not significantly, higher prevalence in cases of combined HPV 6 and HPV 16 infection. Conventional histology and immunocytochemistry could not distinguish CIN associated with HPV 6 from CIN associated with HPV 16 infection.

Human papillomavirus (HPV), in particular HPV types $6,11,16$, and 18 , have been associated with the aetiology of cervical neoplasia. ${ }^{1-3}$ HPV types 6 and 16 account for most HPV infection in the female lower genital tract in Great Britain, ${ }^{4}$ and they seem to have different tumorigenic potential. HPV type 6 is found most commonly in cervical condylomata acuminata and cervical intraepithelial neoplasia (CIN) of lower grades while HPV type 16 is associated with $\mathrm{CIN}$ of more severe grades ${ }^{15}$ and invasive cancer. ${ }^{6}$ Knowledge of the type of HPV associated with CIN in an individual patient might be of prognostic importance.

To date, it has not been possible to grow HPV in culture. Typing is performed with the DNA-DNA hybridisation technique, which demands extensive technical experience and expertise. It would be advantageous if histological features could be identified to distinguish CIN associated with HPV type 6 from type 16 infection. Gross ${ }^{7}$ reported HPV type specific cytopathic effects recognisable on routine histology for HPV types 3, 4, and 6, and, in a small study

Accepted for publication 29 May 1986
Crum $^{8}$ suggested that the presence of HPV type 16 in cervical flat warts may be predicted by the presence of abnormal mitoses.

The purpose of this study was to investigate if HPV type 6 and type 16 produce different and discriminatory cytopathic effects in CIN recognisable by conventional histology and to investigate the prevalence and pattern of the expression of HPV viral antigen in both types of infection.

\section{Material and methods}

\section{STUDY GROUP}

Patients were drawn from a cohort of women attending a district colposcopy clinic who participated in a recent study of the prevalence of different types of HPV in the uterine cervix. ${ }^{5}$ Because of the lower prevalence of HPV type 6 in CIN, all the patients with HPV 6 DNA in their lesions were included in the study. Thirty patients were randomly selected from the group with HPV 16 DNA and another 10 patients with no HPV DNA sequences were also studied. In the study on HPV antigen expression a larger group (42 cases) was selected from patients with HPV 16. 
Table 1 Histological features studied

1 Presence and pattern of koilocytosis

2 Epithelial thickness

3 Nuclear polarity

4 Coarse nuclear chromatin pattern

5 Nuclear vacuolation

6 Binucleation

7 Multinucleation

8 Giant irregular nuclei

9 Individual cell dyskeratosis

10 Abnormal mitoses

11 Hyperkeratosis and parakeratosis

12 Glands affected

13 Loss of distinct cell layers

14 Loss of cytoplasmic maturation

15 Loss of nuclear maturation

16 Nuclear crowding

17 Nuclear pleomorphism

18 Nuclear enlargement

19 Pyknosis

20 Cell bridges

21 Epithelial pearls

\section{HISTOLOGICAL STUDY}

Whenever possible, colposcopically directed cervical biopsies were bisected; one half was used for the DNA-DNA hybridisation study, as detailed elsewhere,${ }^{5}$ and the other half for routine histology and immunocytochemistry. In some cases two adjacent biopsy specimens from the same lesion were used. For histology and immunocytochemistry the biopsy specimen was fixed in formol sublimate solution, and each biopsy specimen was cut at three different levels. Sections for histology were stained with haematoxylin and eosin, and up to three histologically distinct areas were selected from each case for detailed study of the presence of various histological features listed in table 1 without prior knowledge of the type of HPV DNA isolated. Abnormal mitoses were classified into dispersed, clumped, and multipolar mitoses. ${ }^{9}$

\section{IMMUNOCYTOCHEMISTRY}

Expression of HPV antigen was studied in paraffin embedded sections using the indirect immunoperoxidase method. Wax was removed in xylene and alcohol and endogenous peroxidase blocked with $0.5 \%$ hydrogen peroxide in methanol solution. Sections were rehydrated in Tris buffered saline $(\mathrm{pH} 7 \cdot 4)$ solution and then incubated overnight with primary antisera raised in rabbit against a genus specific bovine papillomavirus antigen (Dako B580) at 1/1000 dilution. After two washes in Tris buffered saline solution sections were incubated with peroxidase conjugated swine antirabbit antisera (Dako P217) at $1 / 35$ dilution for 45 minutes. All incubations were performed in a humidified chamber. The peroxidase reaction was developed in freshly prepared $0.5 \%$ $3,3^{\prime}$-diaminobenzene in $0.01 \%$ hydrogen peroxide solution and the sections were counterstained with haematoxylin.

Sections known to be positive for HPV antigen were used as positive controls. Duplicate sections from cases studied were incubated with normal rabbit serum instead of anti-HPV serum as negative controls.

\section{STATISTICAL ANALYSIS}

The significance of the difference in the prevalence of each feature studied was tested using the $\chi^{2}$ test with Yate's correction for small samples. The significance of the difference of means for epithelial thickness was analysed using Student's unpaired $t$ test.

\section{Results}

The 58 cases studied were divided into four groups according to the type of HPV DNA detected (table 2) Twenty seven cases $(46.6 \%)$ had three and 18 cases $(31.0 \%)$ had two histologically distinct areas of different grade of CIN while only 13 cases $(22.4 \%)$ were histologically homogeneous. The number of different areas present in individual cases was unrelated to the type of HPV DNA detected. A total of 130 different areas were studied. The distribution of these areas according to histological diagnosis (table 3) reflects the association of HPV 6 with simple warty lesions, immature metaplasia, and CIN of lower grades and the association of HPV 16 with CIN of higher grade. All the cases with detectable HPV DNA sequences showed at least one histologically recognisable feature of HPV infection, and 36 of 48 cases $(75.0 \%)$ showed more than three histological features of HPV infection. A variable degree of koilocytosis was found in $\mathbf{4 5}$ of $\mathbf{4 8}$ cases $(\mathbf{9 3 . 8 \%})$.

Table 2 No of cases according to HPV type and histology

\begin{tabular}{lllll}
\hline & & \multicolumn{2}{l}{ Overall histological diagnosis } \\
\cline { 3 - 5 } HPV type & No of cases & CIN 1 & CIN 2 & CIN 3 \\
\hline 6 & 8 & 4 & 1 & 3 \\
16 & 30 & 3 & 3 & 24 \\
$6+16$ & 10 & 1 & 0 & 4 \\
None & 10 & 1 & 5 & 40 \\
Total & 58 & 9 & 9 & 40 \\
\hline
\end{tabular}

Overall histological diagnosis 
Table 3 No of different histologically distinct areas

\begin{tabular}{|c|c|c|c|c|c|c|}
\hline \multirow[b]{2}{*}{ HPV type } & \multicolumn{6}{|c|}{ Histological diagnosis } \\
\hline & $\begin{array}{l}\text { Atypical } \\
\text { immature } \\
\text { metaplasia }\end{array}$ & $\begin{array}{l}H P V \\
\text { infection }\end{array}$ & $C I N I$ & CIN 2 & CIN 3 & Total \\
\hline $\begin{array}{l}6 \\
16 \\
6+16 \\
\text { None }\end{array}$ & $\begin{array}{l}5 \\
3 \\
1 \\
3\end{array}$ & $\begin{array}{l}0 \\
4 \\
1 \\
3\end{array}$ & $\begin{array}{r}4 \\
10 \\
2 \\
3\end{array}$ & $\begin{array}{r}4 \\
18 \\
4 \\
6\end{array}$ & $\begin{array}{r}3 \\
35 \\
14 \\
7\end{array}$ & $\begin{array}{l}16 \\
70 \\
22 \\
22\end{array}$ \\
\hline Total & 12 & 8 & 19 & 32 & 59 & 130 \\
\hline
\end{tabular}

Of the 10 cases without detectable HPV DNA, two showed three or more histological features of HPV infection, and another six cases showed at least one feature of HPV infection. One of these cases was positive for HPV antigen. These 10 cases were excluded in the analysis of histological features related to HPV types 6 and 16 infection.

Epithelial thickness determined by the number of cell layers showed a wide range from area to area, regardless of the severity of CIN. The mean (SD) number of cell layers was 19.2 (6.6) for HPV 6, 21.6 $(9 \cdot 1)$ for HPV 16, and 18.0 (8.6) for combined HPV 6 and 16 associated CIN. The difference between the means was not significant. There was also no significant difference in loss of nuclear polarity, nuclear vacuolation, or coarse chromatin pattern between the types of HPV infection.

Koilocytosis showed wide variation in vertical and horizontal extent in both HPV 6 and 16 infection. The shapes of the nuclei within koilocytes were also very variable, with rounded, irregular, cigar and sickleshaped nuclei being seen. The nuclei could be either in a peripheral or central position. There were no significant differences between HPV 6 and 16 infection. Other features of HPV infection (binucleation, multinucleation, single giant nuclei, and individual cell dyskeratosis) were often seen (table 4) and seemed to be commoner in HPV 16 associated lesions. The difference in the prevalence between the study groups, however, did not achieve significance.

Abnormal mitoses were found in five of eight cases (62\%) of HPV 6, 15 of 30 cases ( $50 \%$ ) of HPV 16 , and six of 10 cases $(60 \%)$ of combined HPV 6 and 16 associated lesions. In the different areas studied abnormal mitoses were not found in the simple warty lesions but were present in $31 \%$ of CIN $1,50 \%$ of CIN 2, and $46 \%$ of CIN 3 areas (table 5). All the 26 cases showed a mixture of dispersed and clumped abnormal mitoses. Multipolar mitoses were also seen in two cases from the group with HPV 16 infection.

HPV antigen was shown in 24 of 60 cases $(40 \%)$ and was usually found in koilocytotic areas. The prevalence showed an inverse relation to the severity of the disease. In areas of CIN 3, in particular those showing classical carcinoma in situ, HPV antigen was rarely shown but was found sometimes in the adjacent areas showing milder disease. The prevalence of antigen expression was $37 \cdot 5 \%$ for HPV $6,38 \cdot 1 \%$ for HPV 16 , and $50 \%$ for combined HPV 6 and 16 associated lesions. The differences were not significant.

\section{Discussion}

None of the features studied permitted discrimination between HPV 6 and HPV 16 infection. All the cases with detectable HPV DNA showed at least one histologically recognisable feature of HPV infection, and most $(75 \%)$ showed more than three features. Koilocytosis, a pathognomonic feature of HPV infection, ${ }^{10}$ occurred in $93.5 \%$ of cases, and the pattern was common to HPV 6 and HPV 16 associated lesions. Nuclear morphological changes and the prevalence and location of viral antigen expression were similar in HPV 6 and HPV 16 associated CIN.

Abnormal mitoses were found in CIN of all grades of severity, although they were commoner in more severe disease and seemed to be a useful diagnostic feature of CIN. Abnormal mitoses, even when separated into different types, carried no discriminatory value between HPV 6 and HPV 16 infection. This finding contrasts with that of the study of Crum et al, ${ }^{8}$ in which a similar prevalence of abnormal mitoses was found in a group of 26 cases, but seven of their 10 cases with abnormal mitoses had HPV 16 DNA, and Table 4 Histological features according to HPV type

\begin{tabular}{llll}
\hline & \multicolumn{2}{l}{ Prevalence (\%) } \\
\cline { 2 - 4 } $\begin{array}{l}\text { Histological } \\
\text { feature }\end{array}$ & $\begin{array}{l}H P V 6 \\
(n=16)\end{array}$ & $\begin{array}{l}H P V 16 \\
(n=70)\end{array}$ & $\begin{array}{l}H P V 6 / 16 \\
(n=22)\end{array}$ \\
\hline $\begin{array}{l}\text { Koilocytosis } \\
\text { Binucleation }\end{array}$ & 89 & 91 & 94 \\
$\begin{array}{l}\text { Multinucleation } \\
\text { Giant irregular }\end{array}$ & 69 & 70 & 82 \\
$\begin{array}{l}\text { nuclei } \\
\text { Individual cell } \\
\text { dyskeratosis }\end{array}$ & 63 & 63 & 68 \\
\hline
\end{tabular}


Table 5 Abnormal mitoses according to diagnosis and HPV type

\begin{tabular}{|c|c|c|c|c|}
\hline \multirow[b]{2}{*}{ Histological grade } & \multicolumn{4}{|c|}{ Prevalence (No of areas) } \\
\hline & (6) & (16) & $(6 / 16)$ & Total \\
\hline $\begin{array}{l}\text { Atypical immature } \\
\text { metaplasia } \\
\text { HPV infection } \\
\text { CIN } 1 \\
\text { CIN } 2 \\
\text { CIN } 3\end{array}$ & $\begin{array}{l}0 / 5 \\
0 \\
2 / 4 \\
3 / 4 \\
2 / 3\end{array}$ & $\begin{array}{c}0 / 3 \\
0 / 4 \\
3 / 10 \\
8 / 18 \\
16 / 35\end{array}$ & $\begin{array}{l}0 / 1 \\
0 / 1 \\
0 / 2 \\
2 / 4 \\
6 / 14\end{array}$ & $\begin{array}{c}0 / 9 \\
0 / 5 \\
5 / 16 \\
13 / 26 \\
24 / 52\end{array}$ \\
\hline Total & $\begin{array}{l}7 / 16 \\
(44 \%)\end{array}$ & $\begin{array}{l}27 / 70 \\
(39 \%)\end{array}$ & $\begin{array}{l}8 / 22 \\
(36 \%)\end{array}$ & $\begin{array}{l}42 / 108 \\
(39 \%)\end{array}$ \\
\hline
\end{tabular}

HPV 6 DNA was not detected in any case with abnormal mitoses. Crum et al claimed on this basis that the presence of HPV 16 in the cervix can be predicted by the presence of certain types of abnormal mitoses. The small number in their study with abnormal mitoses may bias the findings in favour of HPV 16, as this is the commonest virus found in CIN. ${ }^{5}$ The lack of detailed histological information on their biopsy specimens, particularly the presence and grade of CIN also makes direct comparison difficult. Crum et al did not distinguish between simple warty lesion and CIN, and the HPV type 6 positive cases studied may not have been CIN but simple warty lesions.

The range of cytopathic effects, including the presence of abnormal mitoses and viral capsid antigen expression, in cervical epithelium is similar for HPV 6 and HPV 16. Conventional histology and HPV common antigen staining are unable to distinguish CIN associated with HPV 6 from that associated with HPV 16 infection.

We thank Mr R Yabsley, Mr P Maddox and staff of the department of histopathology for their cooperation. We also thank Dr JL Dyson for her helpful comments in the preparation of this manuscript.

\section{References}

1 Singer A, Walker PG, McCance DJ. Genital wart virus infection: nuisance or potentially lethal? Br Med J 1984;288:735-7.
2 Zur Hausen H, Gissmann L, Schlehoffer JR. Viruses in the aetiology of human genital cancer. Progress in Medicine and Virology 1984;30:170-86.

3 Gissmann L. Papillomaviruses and their association with cancer in animals and man. Cancer Survey 1984;3(1):161-82.

4 McCance DJ, Clarkson PK, Dyson JL, Walker PG, Singer A. Human papillomavirus type 6 and 16 in multifocal intraepithelial neoplasia of female genital tract. $\mathrm{Br} J$ Obstet Gynaecol 1985;92(11):1093-100.

5 McCance DJ, Campion MJ, Clarkson PK, Chester PM, Jenkins $D$, Singer A. The prevalence of human papillomaviruses type 16 DNA sequences in cervical intraepithelial neoplasia and invasive carcinoma of the cervix. Br $\mathrm{J}$ Obstet Gynaecol 1985;92(11):1101-5.

6 Durst M, Gissmann L, Ikenberg H, zur Hausen H. Papillomavirus DNA from a cervical carcinoma and its prevalence in cancer biopsy samples from different geographical regions. Proc Natl Acad Sci USA 1983;80:3812-5.

7 Gross G, Pfister H, Hagedorn M, Gissmann L. Correlatio between human papillomavirus type and histology. $J$ Inverf Dermatol 1982;78:160-4.

8 Crum CP, Ikenberg H, Richart RM, Gissmann L. Human papi H $^{*}$ lomavirus type 16 and early cervical neoplasia. $N$ Engl $J$ Med 1984;310:880-3.

9 Winkler B, Crum CP, Fugii T, et al. Koilocytotic lesions of the cervix: the relationship of mitotic abnormalities to the presence of papillomavirus antigens and nuclear DNA content. Cancer 1984;53:1081-7.

10 Reid R, Stamhope R, Herschman BR, Booth E, Phibbs GD, Smith JP. Genital warts and cervical cancer. I. Evidence of an association between subclinical papillomavirus infection and cervical malignancy. Cancer 1982;50:377-87.

Requests for reprints to: Dr D Jenkins, Consultant Histopathologist, Whittington Hospital, St Mary's Wing, Highgate Hill, London N19 5NF, England. 